\title{
Preexposure to contextual stimuli: Effects on startle responding in humans
}

\author{
JACQUELYN CRANNEY and RODERICK ASHTON \\ University of Queensland, St. Lucia, Brisbane, Queensland, Australia
}

\begin{abstract}
Previous research with rats has shown that preexposure to the contextual stimuli of the experimental situation results in facilitated habituation of the startle reflex. These findings support the predictions of nonrepresentational theories of habituation (e.g., Groves \& Thompson, 1970), and oppose the predictions of representational theories (e.g., Wagner, 1976). The current experiment was designed to test whether the same results could be obtained with humans. Twentyfour hours prior to the habituation test, one group of subjects (E-P) was exposed to the contextual stimuli of the experimental situation, a second group (C-E) was exposed to different contextual stimuli, and a third group (C-N) received no pretreatment. The habituation test consisted of two sessions of 15 startle-eliciting noise bursts. The P-E group responded less on the first trial of Session 2. This finding is suggestive of greater long-term response decrements in this group, and thus supports the nonrepresentational theories of habituation.
\end{abstract}

The effect of exposure to a context in which responding to a particular stimulus is monitored has recently received attention in both the human (e.g., Ohman, 1979) and the nonhuman (e.g., Fanselow, 1984) literature. The current study is concerned with the effect of preexposure to the experimental context on the amplitude and habituation of the eyeblink reflex in humans.

In the nonhuman literature there are some reports (e.g., Korn \& Moyer, 1966; Marlin \& Miller, 1981) that preexposure to the startle apparatus reduces the amplitude of the acoustic startle reflex while having no apparent effect on long-term habituation. These authors argue that novel apparatus cues induce an amplitude-enhancing arousal effect, which is attenuated by preexposure to the apparatus.

In contrast to these findings, Borszcz, Cranney, and Leaton (1985) have reported that preexposure does not affect the amplitude of the initial startle response in rats, but does result in more rapid long-term decrements of the acoustic startle reflex. Their preexposed animals also developed significantly less freezing behavior during habituation training. Borszcz et al. argue that freezing develops through the association of apparatus cues (CS) with the initially aversive startle stimulus (US), and that freezing reflects a long-term, associatively based sensitization process which enhances startle responding, thereby masking the long-term decrements associated with habituation.

We thank J. T. Lyndon for his invaluable technical assistance, and the Occupational Therapy Department at the University of Queensland for their generous loan of the Medilek unit. We would also like to thank two anonymous reviewers for their insightful comments. Research support from a University of Queensland Special Projects Grant is gratefully acknowledged. This study was conducted while J. Cranney was a University of Queensland postdoctoral research fellow. Requests for reprints should be sent to J. Cranney, who is now at the School of Psychology, University of New South Wales, P.O. Box 1, Kensington, N.S.W. 2033, Australia.
These notions extend Groves and Thompson's (1970) original dual-process theory. In that theory, sensitization is considered to be a short-term, state-dependent process, that may be subject to associative influences. Borszcz et al. (1985) argue that associative mechanisms allow the sensitization process to have long-term effects.

The findings of both Marlin and Miller (1981) and Borszcz et al. (1985) contradict predictions based on Wagner's $(1976,1979)$ associative theory of habituation. Within the latter framework, long-term habituation reflects the retrieval of a memorial representation of the startle stimulus from long-term to short-term (or working) memory. This associatively generated "priming" is purportedly the consequence of exposure to contextual cues that became associated with the startle stimulus during initial training. Priming thus results in less processing of the stimulus, which, in turn, results in a decrement in the amplitude of the startle reflex. On the basis of these arguments, it can be deduced that exposure to the startle apparatus prior to initial habituation training should result in latent inhibition of the association between contextual stimuli and the startle stimulus. Given that the formation of this association is the mechanism of long-term habituation (Wagner, 1976, 1979), development of long-term habituation will be delayed. To date, there is no independently published evidence to support this prediction from Wagner's $(1976,1979)$ theory.

The current study was designed to investigate the effects of preexposure to the experimental context on the initial amplitude and subsequent habituation of the startle reflex in humans, as indexed by changes in eyeblink amplitude and skin conductance. The eyeblink reflex is the most stable component of the startle reflex pattern in humans (Hoffman \& Ison, 1980; Landis \& Hunt, 1939); skin conductance may index different levels of information processing (Ohman, 1979; Siddle, 1985). 
In this experiment, one group of subjects received preexposure to the experimental context (experimentalpreexposed, E-P), one control group received preexposure to a different context (control-exposed, C-E), and another control group received no treatment prior to the habituation test (control-naive, C-N). On the basis of Borszcz et al.'s (1985) findings with rats, it was expected that the preexposed group would differ from the other groups only in showing greater evidence of long-term decrements in responding. In contrast, one can predict, from Wagner's (1976) theory, that the preexposed group would differ from the other groups in showing less evidence of longterm decrements in responding.

\section{METHOD}

\section{Subjects}

The subjects were 47 undergraduate students at the University of Queensland; 31 participated as part of a course requirement, and the remainder participated for payment $(\$ 3.50$ per hour). The subjects were assigned randomly to one of the three treatment conditions. Ten subjects failed to meet the criterion for initial response level (average peak EMG amplitude of the first two responses greater than $200 \mu \mathrm{V}$; see below); the data of 1 additional subject were lost due to equipment failure. The mean age of the remaining subjects was 20.1 years $(S D=3.4)$. There were more females than males in all groups (7:5 in E-P, 9:3 in C-E, 11:1 in C-N); this overall preponderance of females reflected the sex distribution in enrollments.

\section{Apparatus}

The reflex-eliciting stimulus was a 50 -msec white-noise burst, with an instantaneous rise/fall, presented through Sonic Type A 8$\Omega$ stereophonic headphones. Intensity was $104 \mathrm{~dB}$ (SPL), and was calibrated (re $20 \mu \mathrm{Pa}$ ) using a Bruel and Kjaer sound-level meter (Type 2205) with a Bruel and Kjaer microphone (Type 4417). All stimulus durations and intertrial intervals were controlled by solid state programming modules.

Eyeblink magnitude was indexed by the activity of the orbicularis oculi muscles, which control eyelid movement. Two miniature surface electrodes (Beckman Type 650414) were attached to the skin immediately lateral to each temporal canthus and $1-2 \mathrm{~cm}$ ventromedial to this site. A ground electrode was placed on the temple. The interelectrode impedence was less than $15 \mathrm{~K} \Omega$. Following amplification by a Medilek preamplifier (PA89), the EMG signal was both (1) led to a Medilek MS92a EMG unit, where it was displayed, and (2) full-wave rectified and integrated (Beckman Type 9853A Direct-Average EMG integrator), and then led through Beckman amplifiers with a $30-\mathrm{Hz}$ cutoff, and recorded at a paper speed of $2.5 \mathrm{~mm} / \mathrm{sec}$ on a Beckman R612 Dynograph. Peak EMG amplitudes and response latencies were read directly from the Medilek display. Integrated EMG values were calculated manually from the chart recordings. Because of the high-frequency cutoff, a single spike of integrated EMG activity was recorded; the amplitude of this peak was read to the nearest half-millimeter and transformed into millivolt units according to the polygraph gains employed.

Skin conductance was recorded directly using a constant voltage of $0.5 \mathrm{~V}$ across domed $\mathrm{Ag}-\mathrm{AgCl}$ electrodes in conjunction with $0.05 \mathrm{M} \mathrm{NaCl}$ electrolyte. It was recorded continuously from masked areas on the distal phalanges of the index and third fingers of a subject's nondominant hand using a Beckman skin conductance coupler (Type 9844) and a paper speed of $2.5 \mathrm{~mm} / \mathrm{sec}$. A skin conductance response (SCR) was scored if the SCR was greater than $0.02 \mu$ mho and occurred between 1 and $5 \mathrm{sec}$ following stimulus onset. All evoked responses were range-corrected (Lykken \& Vena- bles, 1971) by dividing each subject's SCR by his or her maximum response. Skin conductance level (SCL) at the onset of the first and last stimulus in each session was also noted.

During habituation testing, the subjects sat in a sound-deadened room separated from the experimenter and the equipment. The subjects were monitored using a closed circuit video system and an intercom.

\section{Procedure}

Pretreatment. Twenty-four hours prior to the habituation test, both E-P and C-E subjects participated in a 30-min pretreatment period. The E-P subjects were told that their physiological responses during relaxation were being measured. Skin was cleaned and the electrodes were attached. The subjects sat quietly for two 10 -min periods, broken by a 7-min period during which they completed the A-State scale of the State-Trait Anxiety Inventory (STAI; Spielberger, Gorsuch, \& Lushene, 1970). The C-E subjects were taken to a different room and told that their performance on various puzzles (sections of the Spatial and Mechanical subtests of the Differential Aptitude Tests) was being measured. The tests were administered over two 10-min periods, broken by a 7-min period during which the subjects completed the A-State scale of the STAI. The C-N subjects did not participate in any pretreatment testing.

Habituation test. The subjects were told that their physiological responses during relaxation, and while listening to tones, were being measured. Skin was cleaned and the electrodes were attached. One minute later, the first of a series of 15 white-noise bursts (ITI = $30 \mathrm{sec}$ ) was presented. Following this first habituation session (Session 1), the subjects completed the A-State scale of the STAI during a 7-min intersession interval. Fifteen white-noise bursts (ITI = $30 \mathrm{~s}$ ) were then presented during the second habituation session (Session 2). Following presentation of the stimuli and removal of electrodes, the subjects completed the A-Trait scale of the STAI. During a postexperimental inquiry, they also rated, on 13-point scales, the aversiveness of the noise burst $(1=$ very unpleasant, $13=$ very pleasant) and the quality of their experience during the experiment $(1=$ very interesting, $13=$ very boring). A wide aversiveness scale was employed so that subsequently a full 7-point scale would be available to rate the aversiveness of the stimulus $(1=$ very unpleasant, $7=$ neutral) without biasing the subject toward rating the stimulus as aversive. A wide experience scale was used to match the appearance of the other scale.

\section{RESULTS}

\section{EMG}

Peak and integrated EMG values correlated significantly $(r=0.69, p<.05)$, and analyses of variance of the two sets of data revealed similar effects. Thus, only the results of the integrated EMG analyses will be described in detail. Figure 1 shows the mean integrated EMG for all 15 trials of each session for each experimental group. An overall analysis of the data indicated a significant decrease in responding over trials $[\mathrm{F}(14,462)=21.85, \mathrm{p}<.05]$ and over sessions $[F(1,33)=41.31, p<.05$. A significant trial $\times$ session interaction $[\mathrm{F}(14,462)=1.99$, $\mathrm{p}<.05]$ indicated that the initial response levels were higher in Session 1 than in Session 2, but terminal response levels were equivalent in the two sessions. The E-P group responded less than the other groups during the first trial of Session $2[\mathrm{~F}(2,33)=3.6, \mathrm{p}<.05: \mathrm{E}-\mathrm{P}$ vs. C-E, $F(1,22)=7.97, p<.05 ;$ E-P vs. C-N, F(1,22) $=3.1, \mathrm{p}=.09^{1} ; \mathrm{C}-\mathrm{E}$ vs. $\mathrm{C}-\mathrm{N}, \mathrm{F}(1,22)=0.94$, 


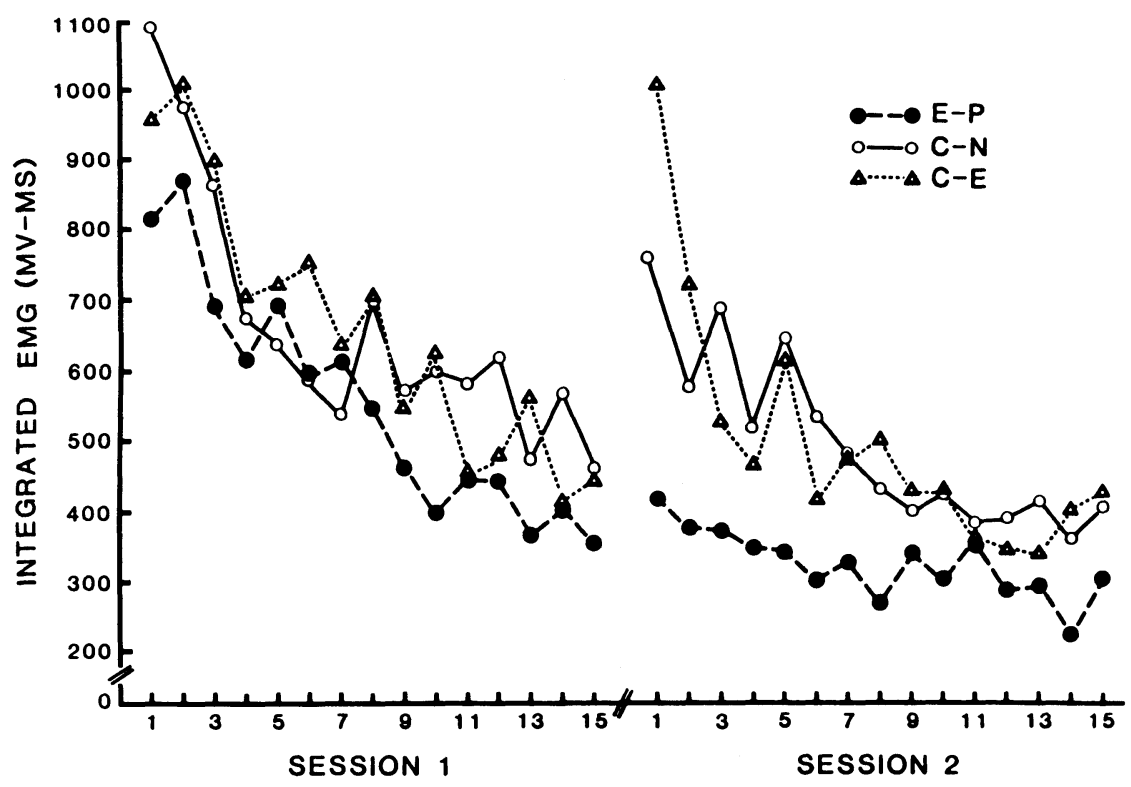

Figure 1. Mean integrated EMG over sessions and trials for each experimental group $(\mathrm{E}-\mathrm{P}=$ experimental-preexposed; $\mathbf{C}-\mathbf{N}=$ control-naive; $\mathbf{C}-\mathbf{E}=$ control-exposed).

$p>$.05]. Similar results were obtained with analyses of female data only, ${ }^{2}$ indicating that the different sex ratios across the groups had no significant impact on response levels. Response latency data are presented in Table 1. Analyses of variance revealed no significant effects.

\section{Skin Conductance}

Table 2 shows SCL at the first and last trials of each session, for each group. The SCL was greater at the first trials than at the last trials $[\mathrm{F}(1,32)=18.9, \mathrm{p}<.05]$, although there was also a significant session $\times$ trial interaction $[F(1,32)=7.43, p<.05]$. For Session 2, response was significantly greater to Trial 1 than to Trial $15[\mathrm{t}(33)=8.04, \mathrm{p}<.05]$; for Session 1 , the difference was not significant. There were no other significant differences.

Table 3 shows the mean SCR amplitude and SCR frequency data for the first and last trials of each session, for each group. Responding in Session 1 was greater than that in Session $2[\mathrm{~F}(1,32)=54.5, \mathrm{p}<.05]$, and responding during first trials was greater than that during last trials $[\mathrm{F}(1,32)=7.6, \mathrm{p}<.05]$. There were no other significant effects. Chi-square analyses of the frequency data revealed no significant group effects.

\section{Ratings}

Table 4 shows the mean values for the STAI and postexperimental inquiry ratings of stimulus aversiveness and experimental experience. Differences in the A-State scale scores were reliable $[\mathrm{F}(2,33)=5.8, \mathrm{p}<.05]$; Tukey tests revealed higher scores for the E-P group than for the control groups $(p<.05)$; scores of the control groups were not significantly different. Differences in rating of the noise burst were also reliable $[\mathrm{F}(2,33)=3.5$, $p<.05]$; Tukey tests further revealed that the E-P group rated the stimulus as less pleasant than did the C-E group $(p<.05)$. No other differences were significant.

\section{DISCUSSION}

The results indicate (1) no differences between groups in initial response levels, (2) no differences in withinsession habituation, and (3) decreased responding by the preexposed group on the initial trial of the second session. These findings indicate that preexposure results in more rapid long-term decrements of the acoustic startle reflex (or, in other words, less recovery across sessions

Table 1

Mean Response Latency (in Milliseconds) for Trials 1 and 15 of Each Session for Each Experimental Group

\begin{tabular}{lccccc}
\hline & \multicolumn{2}{c}{ Session 1 } & & \multicolumn{2}{c}{ Session 2 } \\
\cline { 2 - 3 } \cline { 5 - 6 } Group & Trial 1 & Trial 15 & & Trial 1 & Trial 15 \\
\hline E-P & $39.1(7.2)$ & $39.4(7.5)$ & & $40.6(8.3)$ & $38.8(7.8)$ \\
C-E & $36.3(4.6)$ & $40.5(6.9)$ & & $38.0(5.8)$ & $39.7(10.2)$ \\
C-N & $39.1(4.5)$ & $39.2(6.4)$ & & $38.9(5.3)$ & $41.9(7.7)$ \\
\hline
\end{tabular}

Note-Standard deviations are in parentheses.

Table 2

Mean SCL (Micromhos) for Trials 1 and 15 of Each Session for Each Experimental Group

\begin{tabular}{lccccc}
\hline & \multicolumn{2}{c}{ Session 1 } & & \multicolumn{2}{c}{ Session 2 } \\
\cline { 2 - 3 } \cline { 6 - 6 } Group & Trial 1 & Trial 15 & & Trial 1 & Trial 15 \\
\hline E-P & $4.53(3.44)$ & $4.50(3.67)$ & & $5.53(3.43)$ & $4.13(3.70)$ \\
C-E & $4.83(2.43)$ & $4.38(2.26)$ & & $5.52(2.53)$ & $3.95(2.33)$ \\
C-N & $4.63(1.41)$ & $4.07(1.80)$ & & $4.78(1.45)$ & $3.91(1.87)$ \\
\hline Combined & $4.66(2.52)$ & $4.32(2.65)$ & & $5.29(2.57)$ & $4.00(2.69)$ \\
\hline
\end{tabular}

Note-Standard deviations are in parentheses. 
Table 3

Mean SCR Amplitude (Micromhos) and SCR Frequency Values for Trials 1 and 15 of Each Session for Each Experimental Group

\begin{tabular}{lccccc}
\hline & \multicolumn{2}{c}{ Session 1 } & & \multicolumn{2}{c}{ Session 2 } \\
\cline { 2 - 3 } Response & Trial 1 & Trial 15 & Trial 1 & Trial 15 \\
\hline Amp & $0.86(0.19)$ & $0.31(0.36)$ & $0.52(0.34)$ & $0.20(0.42)$ \\
Freq & 12 & 7 & 11 & 3 \\
& \multicolumn{5}{c}{ Group E-P } \\
Amp & $0.71(0.33)$ & $0.29(0.37)$ & $0.62(0.31)$ & $0.08(0.13)$ \\
Freq & 12 & 7 & 12 & 6 \\
& \multicolumn{5}{c}{ Group C-N } \\
Amp & $0.84(0.18)$ & $0.24(0.27)$ & $0.67(0.32)$ & $0.31(0.65)$ \\
Freq & 12 & 8 & 12 & 6 \\
& & Combined Groups & \\
Amp & $0.80(0.25)$ & $0.28(0.33)$ & $0.60(0.32)$ & $0.20(0.44)$ \\
Freq & 36 & 22 & 35 & 15 \\
\hline Note-Standard deviations are in parentheses.
\end{tabular}

Table 4

Mean STAI Scores, Mean Stimulus Aversiveness Ratings, and Mean Experimental Experience Ratings by Each Experimental Group

\begin{tabular}{lrcc}
\hline & \multicolumn{3}{c}{ Group } \\
\cline { 2 - 4 } Scale & \multicolumn{1}{c}{ E-P } & C-E & C-N \\
\hline A-Trait & $42.3(7.2)$ & $43.3(6.1)$ & $38.8(5.7)$ \\
A-State & $48.2(7.1)$ & $38.1(9.0)$ & $37.2(10.1)$ \\
Stimulus & $4.0(2.1)$ & $5.9(1.7)$ & $4.6(1.6)$ \\
Interest & $5.3(2.6)$ & $5.4(1.4)$ & $4.7(1.5)$ \\
\hline
\end{tabular}

Note-Standard deviations are in parentheses.

from within-session habituation), and corroborate Borszcz et al.'s (1985) findings with rats. As Borszcz et al. argued, these findings support the dual process theory of habituation (Groves \& Thompson, 1970; Thompson, Berry, Rinaldi, \& Berger, 1979), and extend the concept of sensitization from a short-term process to a long-term, associatively based process. That is, the association formed between contextual stimuli and the initially aversive startle stimulus serves to enhance the startle response; this associatively based sensitization process then masks the underlying habituation process.

In contrast to the rat studies (cf. Borszcz et al., 1985), there was no independent index of sensitization in the current study. Although SCL is sometimes used to index general arousal levels (e.g., Champion \& Hodge, 1983), no SCL group differences were found. Because the freezing behavior exhibited by rats consists primarily of a stationary motor pattern, future work with humans could, perhaps, attempt to index sensitization by measuring tonic EMG activity of the orbicularis oculi muscle, since this index is considered to be equivalent to freezing in rats.

One limitation of the current study is that the betweensession interval was shorter than that usually associated with long-term habituation ( $1 \mathrm{~h}$ or longer; Marlin \& Miller, 1981). Thus, the study should be replicated with a longer intersession interval. Nevertheless, the results are comparable to those found by Borszcz et al. (1985), who used an intersession interval of $2 \mathrm{~h}$ with rats. It is conceivable that a much shorter interval produces longterm habituation effects with humans.

We also found that preexposed subjects reported the acoustic stimulus as being more unpleasant than did the other groups. They also showed more state anxiety than did the control groups. These findings may appear to contradict the startle response findings. That is, preexposed subjects responded less on the first trial of Session 2, despite their higher rating of the aversiveness of the acoustic stimulus and their higher state anxiety score. One possible explanation for these results may lie in terms of the predictability of the acoustic startle stimulus. For the nonpreexposed groups, because of the association formed between the two sets of stimuli, the experimental context was highly predictive of the startle stimulus. For the preexposed groups, because of latent inhibition, the experimental context was not highly predictive of the startle stimulus. This lack of predictability could have resulted in greater state anxiety and greater perceived aversiveness of the startle stimulus. Previous studies (Kimmel, Piroch, \& Ray, 1979), on the orienting stimulus, report that aversive stimuli are rated as less intense if they are reliably predicted by preceding stimulus events; this finding is similar to that currently reported for the startle reflex. Previous studies on the orienting reflex have also reported that rated stimulus intensity is not reliably associated with response amplitude (Kimmel et al., 1979). That is, high ratings of stimulus intensity may be associated with either decreased (as currently reported for the startle reflex) or increased responding. Further research could usefully focus on the factors producing these different outcomes.

In summary, the current study has provided some initial findings on the effect of preexposure on the amplitude and habituation of the human eyeblink response. The results indicate that preexposure to the experimental context produces more rapid long-term decrements of the acoustic startle reflex, a finding similar to that reported in the nonhuman literature. Future research should investigate the limitations of the preexposure effect on longterm habituation.

\section{REFERENCES}

Borszcz, G. S., Cranney, J., \& Leaton, R. N. (1985, March). Effects of exposure to the startle apparatus on long-term decrements of the acoustic startle reflex: A long-term sensitization hypothesis. Paper presented at the annual meeting of the Eastern Psychological Association, Boston, MA.

Champion, R. A., \& Hodge, R. (1983). The application of the preparatory-response hypothesis to changes in base skin response. Psychophysiology, 20, 59-62.

FANSELOW, M. S. (1984). Opiate modulation of the active and inactive components of post-shock reaction: Parallels between naloxone pretreatment and shock intensity. Behavioral Neuroscience, 98. 269-277.

Groves, P. M., \& Thompson, R. F. (1970). Habituation: A dual-process theory. Psychological Review, 77, 419-450.

Hoffman, H. S., \& Ison, J. R. (1980). Reflex modification in the domain of startle: I. Some empirical findings and their implications for 
how the nervous system processes sensory input. Psychological Review, 87, 175-189.

Kimmel, H. D., Piroch, J., \& RAY, R. L. (1979). Monotony and uncertainty in the habituation of the orienting reflex. In H. D. Kimmel, E. H. Van Olst, \& J. F. Orlebeke (Eds.), The orienting reflex in humans. Hillsdale, NJ: Erlbaum.

KORN, J. H., \& MOYER, K. E. (1966). Habituation of the startle response and of heart rate in the rat. Canadian Journal of Psychology, 20, 183-190.

Landis, C. \& Hunt, W. A. (1939). The startle pattern. New York: Farrer \& Rinehart.

LykKen, D. T., \& Venables, P. H. (1971). Direct measurement of skin conductance: A proposal for standardization. Psychophysiology, 8, 656-672.

Marlin, N. A., \& Miller, R. R. (1981). Associations of contextual stimuli as a determinant of long-term habituation. Journal of Experimental Psychology: Animal Behavior Processes, 7, 313-333.

OHMAN, A. (1979). The orienting response, attention, and learning: An information-processing perspective. In H. D. Kimmel, E. H. Van Olst, \& J. F. Orlebeke (Eds.), The orienting reflex in humans. Hillsdale, NJ: Erlbaum.

SidDLE, D. A. T. (1985). Effects of stimulus omission and stimulus change on dishabituation of the skin conductance response. Journal of Experimental Psychology: Learning, Memory and Cognition, 11, 206-216.

Spielberger, C. D., Gorsuch, R. L., \& Lushene, R. E. (1970). Manual for the State-Trait Anxiety Inventory. Palo Alto, CA: Consulting Psychologists Press.

Thompson, R. F., Berry, S. D., Rinaldi, P. C., \& Berger, T. W. (1979). Habituation and the orienting reflex: The dual-process theory revisited. In H. D. Kimmel, E. H. Van Olst, \& J. F. Orlebeke (Eds.), The orienting reflex in humans. Hillsdale, NJ: Erlbaum.
Wagner, A. R. (1976). Priming in STM: An information-processing mechanism for the self-generated or retrieval-generated depression in performance. In T. J. Tighe \& R. L. Leaton (Eds.), Habituation: Perspectives from child development, animal behavior, and neurophysiology. Hillsdale, NJ: Erlbaum.

WAGNER, A. R. (1979). Habituation and memory. In A. Dickinson \& R. A. Boakes (Eds.), Mechanisms of learning and motivation: $A$ memorial volume for Jerzy Konorski (pp. 53-82). Hillsdale, NJ: Erlbaum.

\section{NOTES}

1. A similar analysis of peak EMG values revealed a significant difference between $\mathrm{E}-\mathrm{P}$ and $\mathrm{C}-\mathrm{N}[\mathrm{F}(1,22)=4.65, \mathrm{p}<.05]$.

2. An overall analysis of the female data indicated a significant decrease in responding over trials $[F(14,322)=17.4, p<.05]$ and over sessions $[\mathrm{F}(1,23)=34.8, \mathrm{p}<.05]$. A significant trial $\times$ session interaction was obtained $[\mathrm{F}(14,322)=2.8, \mathrm{p}<.05]$, with similar differences to those reported for the main data. The E-P group responded less than the C-E group during the first trial of Session $2[F(1,13)=4.86$, $\mathrm{p}<.05]$; there were no differences between the E-P and C-N groups $[F(1,15)=1.08, p=.32]$ or between the $C-E$ and $C-N$ groups $[F(1,18)$ $=0.72, p=.41]$. Given the difference in response variance in the E-P $(\mathrm{SD}=7.7)$ and $\mathrm{C}-\mathrm{N}(\mathrm{SD}=17.0)$ groups, a Mann-Whitney $\mathrm{U}$ test was conducted; this indicated that the E-P group responded significantly less than did the $\mathrm{C}-\mathrm{N}$ group $(\mathrm{U}=38, \mathrm{p}<.05)$.

(Manuscript received April 18, 1985; revision accepted for publication December 2, 1985.) 